\title{
Rodent paleocommunities from the Oligocene of Ulantatal (Inner Mongolia, China)
}

\author{
HELDER GOMES RODRIGUES*, LAURENT MARIVAUX \& MONIQUE VIANEY-LIAUD \\ Laboratoire de Paléontologie, Institut des Sciences de l'Évolution (UMR 5554, CNRS, UM2, IRD), Université Montpellier 2, cc \\ 064, Place Eugène Bataillon, F-34095 Montpellier Cedex 05, France \\ *corresponding author: helder.gomes.rodrigues@gmail.com
}

\begin{abstract}
The Oligocene deposits of the Ulantatal area in Inner Mongolia (China) contain among the richest mammalian faunas from Asia. To date, only some parts of the rodent faunas have been described. Here, we propose to review the rodent faunal lists for each site, including the description of a few new rodent specimens. We describe three additional rodent species: the Cylindrodontidae Anomoemys lohiculus, the Eomyidae Asianeomys sp., and the Dipodidae Litodonomys huangheensis. This study allows us to constrain the stratigraphic range of Anomoemys lohiculus, which ranged from the late Early Oligocene to the early Late Oligocene in this area. Asianeomys sp. and Litodonomys huangheensis are dated from the latest Oligocene. These Oligocene deposits consist now of more than 70 species of mammals if we include the fauna from Kekeamu. This latter corresponds to the basal part of the Ulantatal Formation and could be dated biochronologically from the earliest Oligocene. When compared to the faunas from the Valley of Lakes in Central Mongolia, the Ulantatal faunas present a great majority of rodents, and this difference can be partly explained by sampling and description biases regarding macro-mammals. This study also shows that variations existed between Inner and Central Mongolia, especially regarding the composition of the rodent paleocommunities. However, the assessment of their evolutionary history in this part of Asia with respect to the important climate and environment changes, require further precisions and more material than current data allow.
\end{abstract}

Keywords: Rodentia, Mammalia, Systematics, late Paleogene, Mongolian Plateau

Submitted 27 March 2014, Accepted 26 May 2014

(C) Copyright Helder Gomes Rodrigues May 2014

\section{INTRODUCTION}

\section{Historical context of the Ulantatal area}

The Ulantatal area is well-known for its Oligocene deposits including some of the most diversified and richest mammalian faunas (Huang, 1982). This area also encompasses Pliocene and Pleistocene deposits. Ulantatal is located about $60 \mathrm{~km}$ north of the small town Bayanhaote, Alxa Zuoqi County. This latter belongs to the Jilantai Basin, which is situated in Inner Mongolia (China; Fig. 1).

The first mammal fossils were unearthed in 1977 by a team of local geologists. The next year, a field campaign, led by scientists from the Institute of Vertebrate Paleontology and Paleoanthropology of Beijing (IVPP, China), established an important collection of fossils involving more than a hundred specimens (Huang, 1982). They were collected on both sides of the small valley of Ulantatal (i.e., "red river" in Mongolian), which consists of mesas alternating with isolated hills. The first relative datings indicated a "Middle Oligocene" age according to comparisons drawn with similar lithological content from the Qingshuiying Formation (Ningxia, China; Huang, 1982) and similar faunal content from the Hsanda Gol Formation (Valley of Lakes, Central Mongolia; Russell \& Zhai, 1987).

In 1987, a second important expedition joining Chinese and German scientists supported by the Academia Sinica (China) and the Max Planck-Gesellschaft (Germany) allowed to investigate the Ulantatal area with precision. This expedition contributed to setting up a more accurate geological map of the region. Three stratigraphical units were defined (Ulan I, II and III), which clearly delineate the stratigraphical position of eight new localities (UTL1-8; Huang, 1992; Fig. 1). Subsequently, the study of the rodent faunas, especially the Ctenodactylidae (Vianey-Liaud et al., 2006) has allowed for a correlation with the contemporaneous faunas from the Valley of Lakes where deposits are dated radiometrically $\left({ }^{40} \mathrm{Ar} /{ }^{39} \mathrm{Ar}\right.$ method; Höck et al. 1999; Daxner-Höck \& Badamgarav, 2007). In this context, the different stratigraphical units of the Ulantatal area were dated (Schmidt-Kittler et al., 2007). The stratigraphical sequence of Ulantatal encompasses a series of deposits of about 60 meters in thickness, and it would extend from the late Early Oligocene to the Late Oligocene, thereby corresponding to about $8 \mathrm{Myr}$ of record (see Vianey-Liaud et al., 2006 for more details about the geological context).

\section{Faunal content of the Oligocene deposits from Ulantatal}

The preliminary study of fossil mammals presented by Huang (1982) mentioned 30 species belonging to 18 genera, representing 16 families distributed among 7 distinct orders, and were found mainly by surface collecting. This list already emphasized the exceptional faunal richness of Oligocene sites from the Ulantatal area, which consist of a wide range of macro and micro-mammals. Since that time, many studies have significantly enhanced the number of species, and have also refined the first descriptions (e.g., Huang, 1984, 1985, 1986, 1987), but the age remains imprecise, especially concerning macro-mammals. Only some rodent faunas were described and accurately dated according to the screen-washing campaign of the eight dated sites performed during the 80's. These faunas included Dipodidae (Huang, 1992; Gomes Rodrigues et al., 2011), Ctenodactylidae (Vianey-Liaud et al., 2006, 2010), Muroidea 


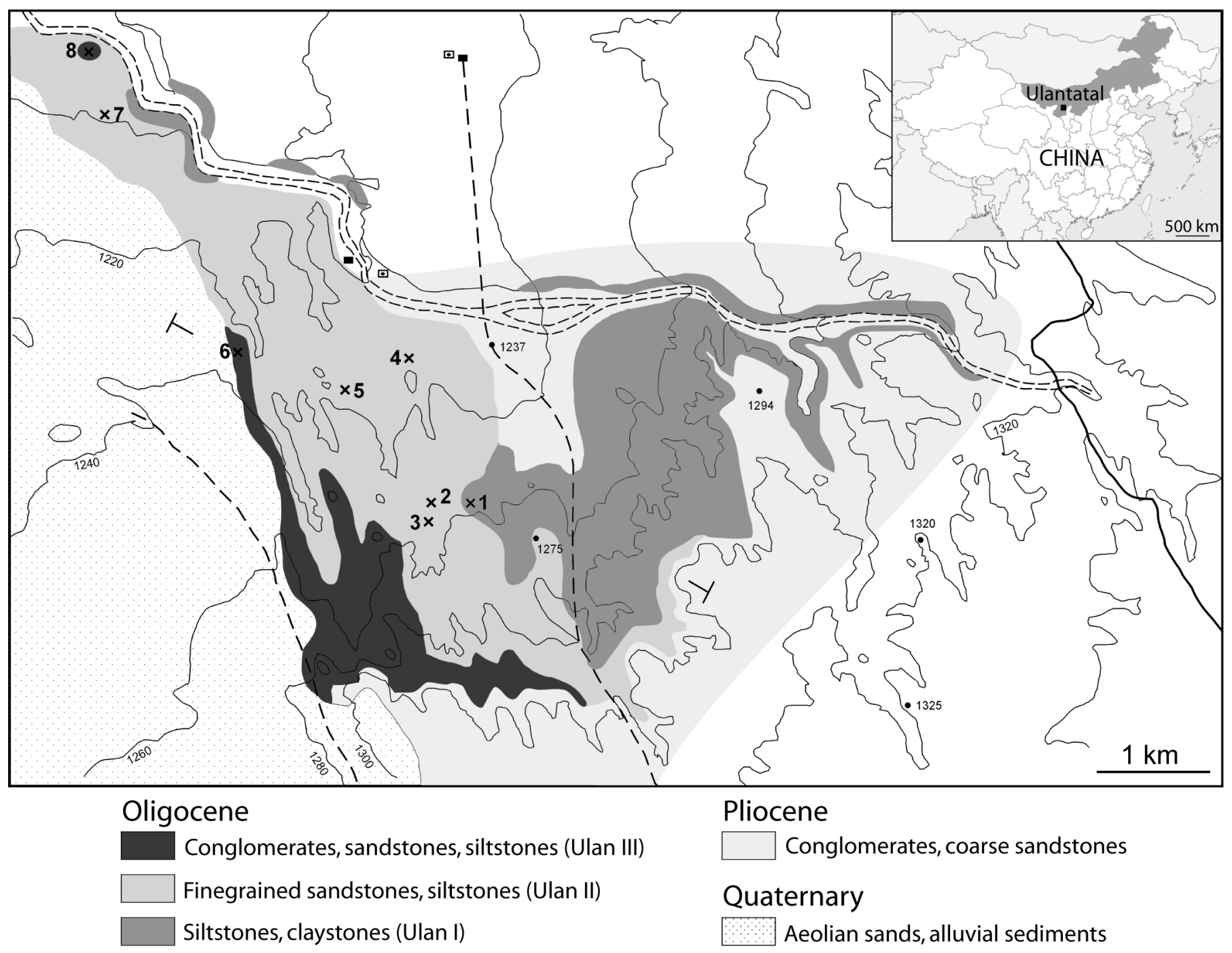

Figure 1. Map showing the location and the geology of the Ulantatal area in Inner Mongolia, China (from Vianey-Liaud et al., 2010 and Gomes Rodrigues et al., 2012a). Numbers correspond to UTL sites.

(Gomes Rodrigues et al., 2012a), and a few Aplodontoidea and Sciuridae (Vianey-Liaud et al., 2013). To date, no revised faunal lists have been erected since the description of these new fossils, including specimens from Kekeamu, which is a small branch of the Ulantatal valley investigated twice by Chinese scientists in 1988 and 1989 (Wang \& Wang, 1991).

The aim of this paper is to describe the additional rodent specimens and to make an overall review of the Oligocene mammalian faunas from Ulantatal. Such a review will be necessary for further discussions about the evolution of the main rodent paleocommunities from the Mongolian Plateau (i.e., Northern China and Central Mongolia).

\section{MATERIAL AND METHODS}

The dental material was described following the classical rodent nomenclature of Wood \& Wilson (1936) involving a few modifications depending on the group investigated (Wang \& Emry, 1991; Marivaux et al., 2004; Gomes Rodrigues et al., 2012a; Fig. 2). Specimens were listed according to the IVPP system. Measurements were made at $0.01 \mathrm{~mm}$ with a measuroscope Nikon 10 linked to a digital counter Nikon CM-6S.

\section{SYSTEMATIC PALEONTOLOGY}

Order RODENTIA Bowdich, 1821

Family CYLINDRODONTIDAE Miller \& Gidley, 1918 Anomoemys Wang, 1986

Anomoemys lohiculus (Matthew \& Granger, 1923)

(Fig. 3A-L)

Holotype. AMNH 19100, left maxillary with P3-M2.

Type Locality. Oligocene, Hsanda Gol Formation, Loh, Mongolia.

Emended Diagnosis. Cheek teeth unilaterally hypsodont; on upper molars, main transverse lophs salient and almost equal in height to each other; protocone mesio-distally elongated, hypocone small and nearly indistinct from the protocone within the primitive endoloph; paracone and metacone incorporated in transverse lophs; metaloph retroverse and incomplete; presence of longitudinal crests connecting the protoconule, metaconule and posteroloph; $\mathrm{P} 4$ with strong parastyle; dp4 with marked mesoconid and strong hypoconulid; p4 with complete metalophulid II, ectolophid straight, entolophid connected to 
A

\section{Lower cheek teeth}
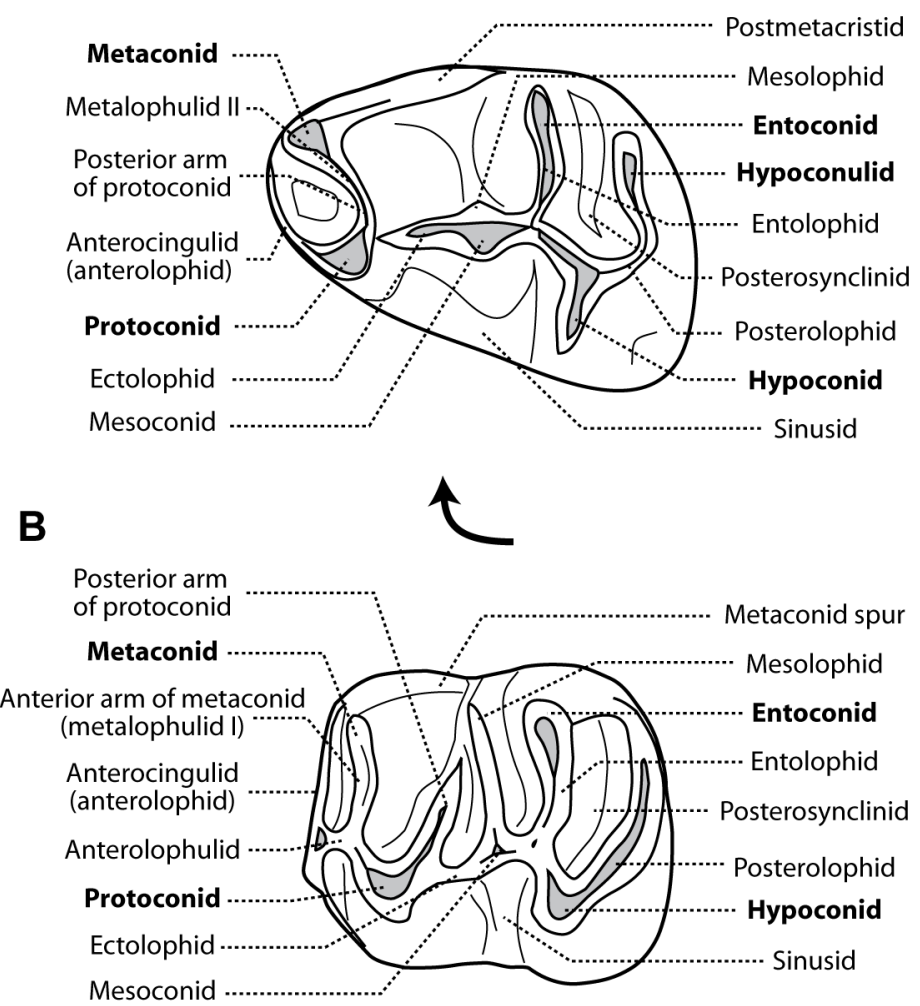
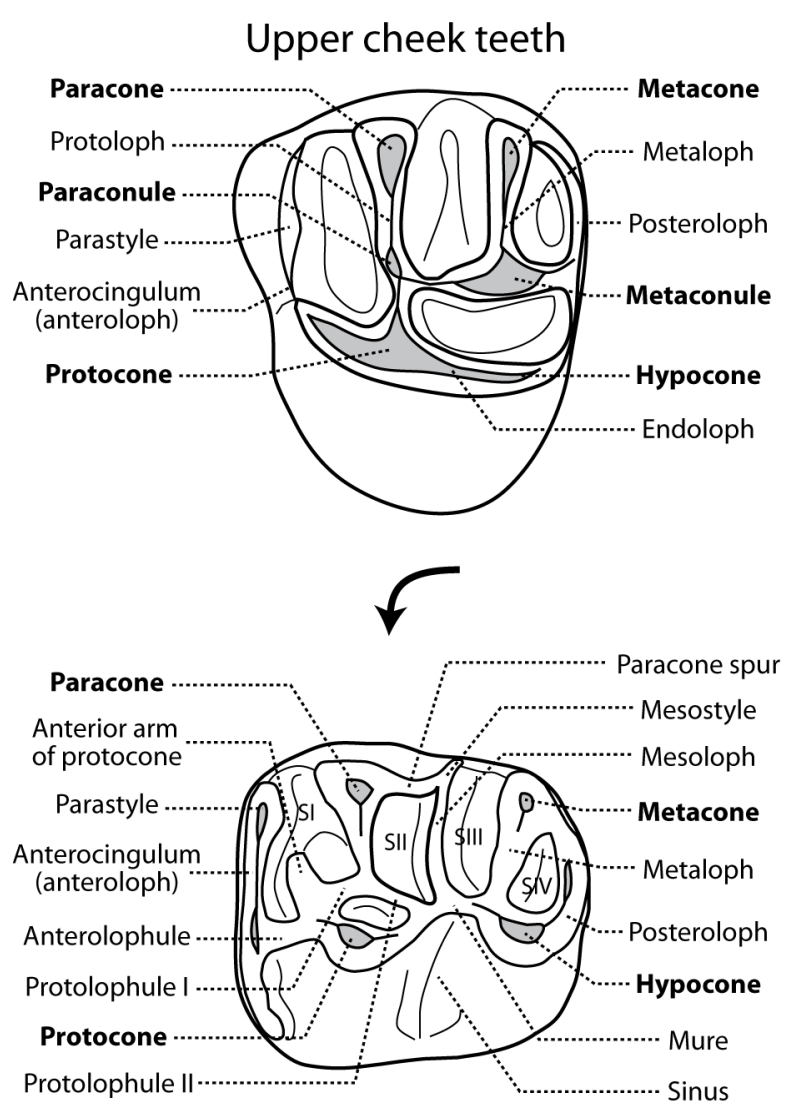

Figure 2. Dental nomenclatures used in this study. A: dp4 and P4 for cylindrodontids. B: m2 and M2 for dipodids and eomyids. SI to SIV correspond to synclines I to IV.

mesoconid or to hypoconulid, hypoconid salient and developed mesio-externally, hypoconulid distinct.

Material. see Table 1.

Stratigraphical Range. UTL1 (Ulan I) and UTL4 (Ulan II), late Early Oligocene and early Late Oligocene, respectively.

\section{Description}

The lower and the upper cheek teeth are lophodont and high crowned except deciduous premolars.

\section{Lower teeth}

On dp4, the protoconid and metaconid are both small (Fig. 3A, D). They are linked by a low anterocingulid and by a well-developed metalophulid II. The metaconid is mesially located compared to the protoconid. A large postmetacristid, probably including an indistinct mesostylid because of high wear, starts from the distal part of the metaconid and extends along the lingual side of the tooth toward the entoconid. The mesolophid is very low and reduced. A low spur starts from the mesial part of the metalophulid II and runs toward this mesolophid. The entolophid meets the mesoconid distally. It includes a hardly distinct entoconid, which is mesiodistally compressed and as high as the hypoconid, and is located on the distal border of the tooth. The hypoconid continues as a strong posterolophid, which is dominated by a mesiodistally compressed and moderately high hypoconulid. The posterosynclinid is open lingually between the hypoconulid and entoconid. Central synclinids are wide and deep.

The $\mathrm{p} 4 \mathrm{~s}$ are wider than large due to the asymmetrical hypsodonty affecting mostly the region of the hypoconid (Fig. 3B-C, E-F). These teeth are also strongly heavily worn as shown by their smoothed border. They have two roots. Lophids include faintly protruding cuspids. The protoconid and metaconid are linked by a short anterolophid. The observation of dp4 is important for the interpretation of homologies, especially for the mesial part of $\mathrm{p} 4$. As a result, a complex cristid constituted by a proverse lingual branch of the mesolophid joins the mesial-most part of the metalophulid II. A lingual cristid starting from the mesial border of the entoconid reaches the mesostylid. In the talonid of one tooth (Fig. 3B), the entolophid is connected to the central part of the ectolophid. On the other one (Fig. 3C), the entoconid is more distal, and the entolophid does not reach the ectolophid, but it is connected to a reduced hypoconulid via a mesio-distal cristid dividing the posterior synclinid in two parts. The posterolophid closes the posterosynclinid and joins the entoconid.

The $\mathrm{m} 1 \mathrm{~s}$ and $\mathrm{m} 2 \mathrm{~s}$ are tetralophodont and possess two mesial roots and one distal (Fig. 3G-H). The anterior synclinid is the most elongated, while the others are equal in size. Homologies can be observed between a pristine tooth (Fig. $3 \mathrm{H}$ ), and dp4 and $\mathrm{p} 4$ morphologies. The mesial synclinid is closed lingually by a cristid linking the metaconid to the mesostylid. Mesially, the anterolophid links both the protoconid and metaconid. The second lophid could be the result of the addition of the posterior arm of the protoconid and the lingual part of a lingual mesolophid. The central and distal synclinids are opened lingually. The entoconid is included in the entolophid, as the metaconid in the anterolophid. The ectolophid is complete and the entolophid reaches a minute mesoconid labially. On the pristine tooth, the hypoconulid is clearly visible on the posterolophid. This lophid does not reach the distal base of the entoconid. 
Table 1. Dental measurements for specimens of Anomoemys lohiculus (in $\mathrm{mm})$.

\begin{tabular}{|c|c|c|c|}
\hline \multicolumn{2}{|c|}{$\begin{array}{l}\text { UTL1 } \\
\text { (IVPP V17669.1 to } 18 \text { ) }\end{array}$} & \multicolumn{2}{|c|}{$\begin{array}{l}\text { UTL4 } \\
\text { (IVPP V17670.1 and 2) }\end{array}$} \\
\hline $\mathrm{dp} 4$ & $2.24 \times 1.64$ & M1 or 2 & $2.39 \times 2.63$ \\
\hline dp4 & - & M3 & $2.14 \times 2.16$ \\
\hline p4 & $2.28 \times 2.35$ & & \\
\hline p4 & $2.38 \times 2.21$ & & \\
\hline $\mathrm{m} 1$ or 2 & $2.72 \times 2.86$ & & \\
\hline $\mathrm{m} 1$ or 2 & $2.58 \times 2.29$ & & \\
\hline $\mathrm{m} 1$ or 2 & - & & \\
\hline P4 & $2.66 \times 3.40$ & & \\
\hline P4 & - & & \\
\hline M1 or 2 & $2.05 \times 2.77$ & & \\
\hline M1 or 2 & $2.14 \times 3.08$ & & \\
\hline M1 or 2 & $2.20 \times 3.17$ & & \\
\hline M1 or 2 & $2.11 \times 2.69$ & & \\
\hline M1 or 2 & $2.06 x-$ & & \\
\hline M1 or 2 & - & & \\
\hline M1 or 2 & - & & \\
\hline M1 or 2 & - & & \\
\hline M3 & $2.3 \times 2.72$ & & \\
\hline
\end{tabular}

\section{Upper teeth}

$\mathrm{P} 4 \mathrm{~s}$ have a strong parastyle, which is elongated transversally (Fig. 3I). The main four lophs have nearly the same height. A short anteroloph joins the prominent protocone. This latter is larger than wide, and it is fused with a minute hypocone on which the posteroloph is connected. The protoconule is reduced and only developed in its mesial part. The metaconule is reduced, but less than the protoconule, and laterally compressed; it is connected to the protoconule mesially and to the posteroloph distally. The paracone and metacone are incorporated in the protoloph and metaloph, respectively, but remain distinct. The metaloph is interrupted in its lingual part, since there is no connection between the hypocone and metaconule. All the synclines are deep and open, except the more distal. Labially, there is neither ectoloph nor mesostyle, but only a weak mesio-labial crest starting from the metacone and reaching the base of the paracone.

The morphology of M1s and M2s (Fig. 3J-K) is close to that of $\mathrm{P} 4 \mathrm{~s}$. However, the parastyle is reduced, elongated, and included in the anteroloph. The paracone and metacone are less distinct. The protocone is less wide and the metacone has a more distal position.

M3s are not greatly elongated distally (Fig. 3L). The metacone is indistinct and the metaloph is lower than other lophs.

Remarks. Although the size of some lower molars appears greater than the size of the holotype (Matthew \& Granger, 1923; Kowalski, 1974), these specimens are assigned to $A$. lohiculus. Huang (1993a) already described some specimens of A. lohiculus from the Ulantatal area, but the material lacked good provenance. Some of these cylindrodontids from Ulantatal could be the first confirmation of this family in the Late Oligocene of Asia. To date, the only cylindrodontid attributed to the Late Oligocene is the doubtful Sespemys thurstony from North America (Walsh \& Storer, 2008).

Family DIPODIDAE Fischer von Waldheim, 1817

Litodonomys Wang \& Qiu, 2000
Litodonomys huangheensis Wang \& Qiu, 2000

(Fig. 3M-N)

Holotype. one right $\mathrm{m} 2$ (IVPP V11768.1).

Type Locality. Late Oligocene, GL 9601B in Shangxigou of Lanzhou Basin, Lower Member of the Xianshuihe Formation, Gansu, China.

Material. 1 M3 (IVPP V17663.1, 0.96x0.95), $1 \mathrm{~m} 3$ (IVPP V17663.2, 1.19x1.02).

Stratigraphical Range. UTL6 (Ulan III), latest Oligocene.

\section{Description \\ Lower teeth}

The $\mathrm{m} 3$ is short and pear-shaped. The anterolophid is present, while the anterolophulid is missing. The protoconid and metaconid are linked via a transverse metalophulid I. The distal spur of the metaconid is marked and nearly reaches the minute entoconid. The ectolophid starts from the posterior arm of the protoconid and reaches the entoconid. As a result, the sinusid is wide and more distally protruding, while the mesolophid is missing. The hypoconid is marked but included in the posterolophid, which is fused with the entolophid.

\section{Upper teeth}

The M3 is rounded. The anteroloph is marked, while the anterolophule is central and reaches the lingual part of the elongated paracone. This cusp is stronger than the protocone, which is small and conical. They are connected by a short protolophule II. The mure is faintly developed, as the endoloph, and it joins the protolophule II. The hypocone is strongly reduced. The metaloph can be either missing or merged with the strong posteroloph. The central syncline is very wide due to the absence of both metacone and mesoloph.

Remarks. These specimens can be attributed to the species Litodonomys huangheensis, because there is no significant difference with respect to the first fossils described from Shangxigou (Eastern Gansu, Xianshuihe Formation; Wang \& Qiu, 2000), except the presence of anterolophid on $\mathrm{m} 3$. However, the M3 from UTL 6 differs from other material from the Valley of Lakes (Daxner-Höck et al., 2014) in having a mure, and its lingual part of the anteroloph clearly separated from the protocone. In general, the specimens found in the Valley of Lakes appear slightly smaller than most of the hypodigm. Such differences could also represent intraspecific variation, which is to date poorly known, but is generally important for third molars in rodents. These $\mathrm{m} 3$ and M3 from UTL6 also differ from those of Litodonomys xishuiensis (Wang, 2003), Litodonomys lajeensis (Li \& Qiu, 1980; Daxner-Höck et al., 2014), and Litodonomys minimus (Kimura, 2010) in being larger, with the distal part far less reduced. Moreover, the material from Ulantatal is contemporaneous with that excavated in Shangxigou (Wang \& Qiu, 2000a), in Yandantu (Wang, 2003), and in the Valley of Lakes (Daxner-Höck et al., 2014).

Family EOMYIDAE Winge, 1887

Asianeomys Wu et al., 2006

Asianeomys sp.

(Fig. 3O-P)

Material. 1 P4 (IVPP V17671.1, 0.91x0.97), 1 M1 or M2 (IVPP V17671.2, 0.92x1.14)

Stratigraphical Range. UTL6 (Ulan III), latest Oligocene 
A
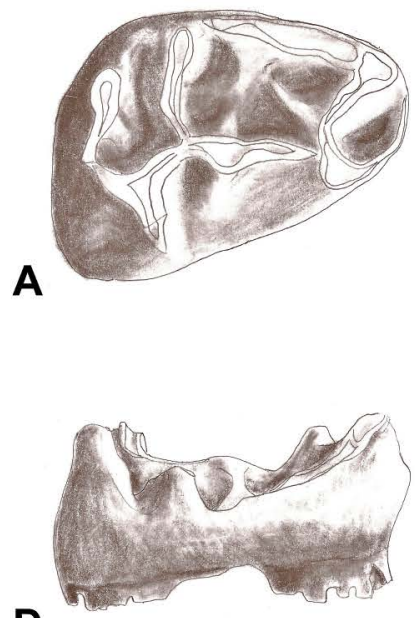

D
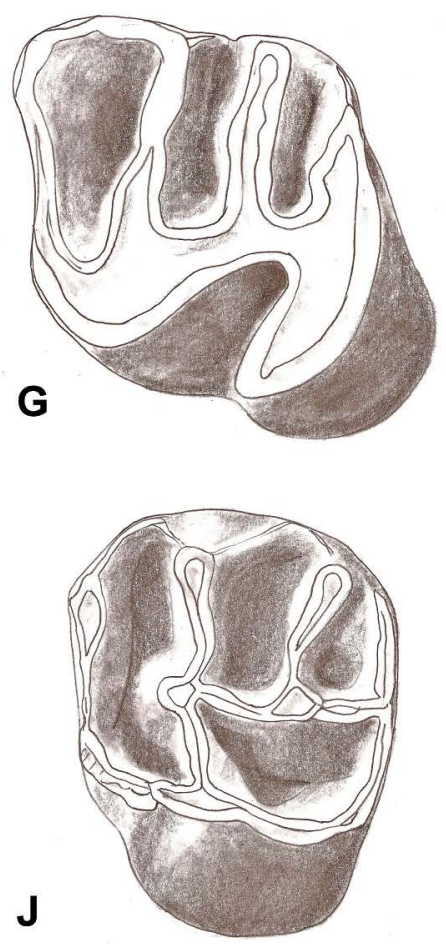

B
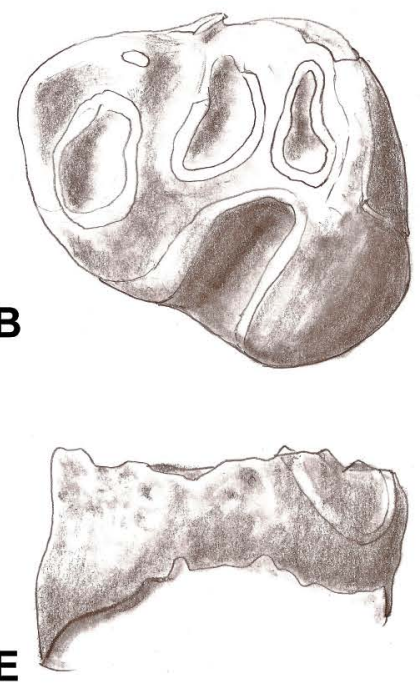

H

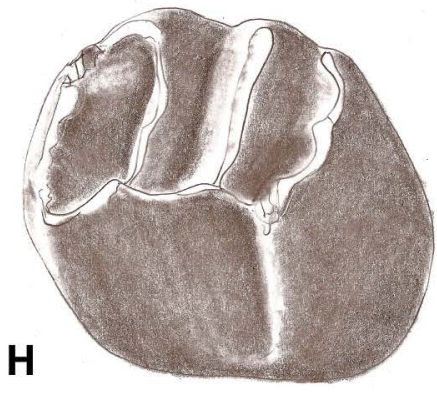

K

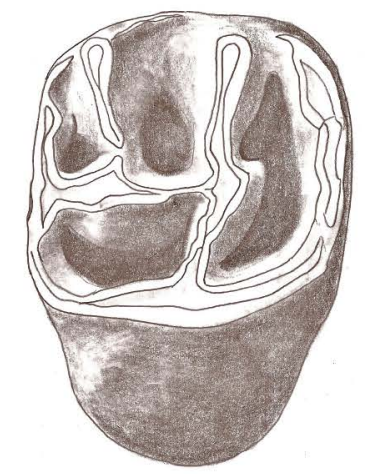

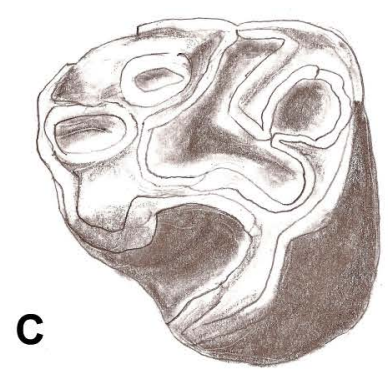

$\mathbf{F}$
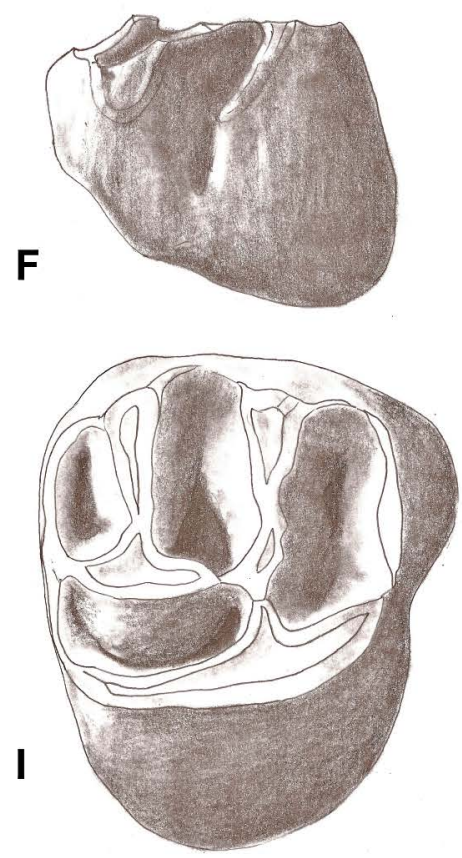

L

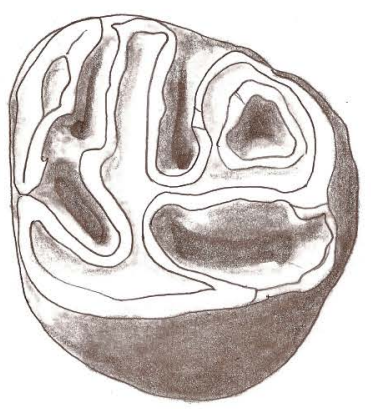

\section{$1 \mathrm{~mm}$}
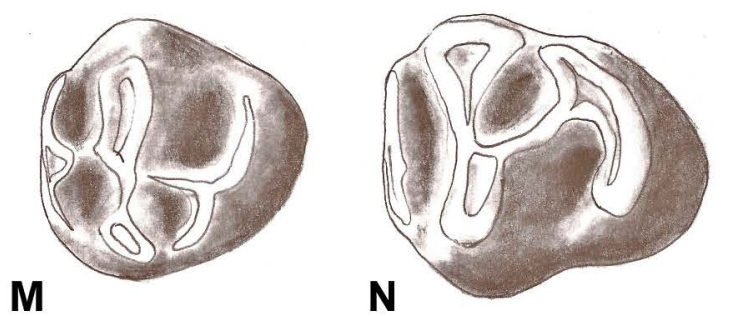

$\mathbf{N}$
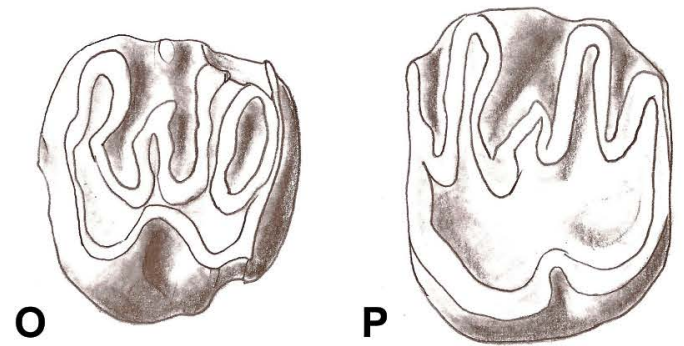

Figure 3. Dental illustrations of Anomoemys lohiculus, Litodonomys huangheensis and Asianeomys sp. A-L: Anomoemys lohiculus UTL1. A, occlusal and D, lingual sides of right dp4; B, occlusal and $\mathbf{E}$, lingual sides of left p4; C, occlusal and $\mathbf{F}$, labial sides of left p4; $\mathbf{G}-\mathbf{H}$, occlusal sides of left M1 or M2; I, occlusal side of right P4; J, occlusal side of left M1 or M2; K, occlusal side of right M1 or M2; L, occlusal side of left M3. M-N: Litodonomys huangheensis, UTL6; occlusal sides of left M3 and m3. O-P: Asianeomys sp., UTL6; occlusal sides of left DP4 and M1. 


\section{Description \\ Upper teeth}

The P4 is worn. The anteroloph is rudimentary and the syncline I is absent. The protolophule I, which links the protocone and paracone, is curved mesiodistally. The mesoloph is moderately enlarged and distally curved. It extends the mesial part of the mure. The syncline II is narrow. The mesostyle is distinct but poorly developed. The transverse metaloph links the anterior arm of the hypocone. The paracone and metacone are transversally elongated. The posteroloph joins the base of the metacone and closes the syncline IV. The sinus is slightly proverse.

The M1 or M2 (extremely worn) is wider than large. The anteroloph reaches the labial side. The syncline I is open. The protoloph I joins the protocone and paracone. A crest distally starting from the paracone follows the labial margin toward the metacone. The mesoloph is curved toward the distal part of the tooth. The mesostyle is absent. The transverse metaloph meets the anterior arm of the hypocone. The metacone is distinct, but included in the strait metaloph. The posteroloph does not reach the base of the metacone and the syncline IV remains open as a result.

Remarks. Asianeomys sp., like other Asianeomys samples, has a bunolophodont pattern with highly developed lophs, with rudimentary to absent anteroloph and syncline I on P4, and with the mure connected to the distal arm of the the protoloph. It presents the same size as the Chinese Asianeomys asiaticus (Wang \& Emry, 1991), Asianeomys dangheensis (Wang, 2002; Maridet et al., in press) and Asianeomys junggarensis (Wu et al., 2006), while it is slightly smaller than Asianeomys engesseri (Wu et al., 2006), and greater than Asianeomys fahlbuschi (Wu et al., 2006) and the Kazak Asianeomys bolligeri (Lopatin 2000, 2004; Maridet et al., in press). It differs from Asianeomys asiaticus in having a shorter prelobe and a mesoloph on $\mathrm{P} 4$, and in the presence of a distal paracone crest and the absence of mesostyle on M1-2. It differs from Asianeomys junggarensis and Asianeomys dangheensis in having a syncline I absent on P4 and shorter mesoloph. It differs from Asianeomys engesseri and fahlbuschi in having a transverse metaloph on M1 or M2. It also differs from Asianeomys bolligeri in having a curved mesoloph, and in not having a lingual arm of anteroloph on M1-2. Most of the characters discussed here are frequently highly variable, and it cannot be excluded that Asianeomys sp. actually belongs to one of these species, an issue which can be addressed only when additional material will be found.

\section{DISCUSSION}

\section{Updated mammalian faunal lists of Ulantatal}

Kekeamu corresponds to the basal part of the Ulantatal Formation (Wang \& Wang, 1991). This fauna includes 11 species encompassing 10 families (Tables 2 and 3). Among them, rodents are predominantly represented and include one cylindrodontid, one aplodontid, one dipodid, two muroids, and two ctenodactyloids, which need re-examination because some species were not precisely assigned. Two Kekeamu taxa have been described: the ctenodactyloid, Ageitonomys neimongoliensis (Wang, 2010) and Ardynomys sp. (Wang \& Meng, 2009). According to the presence of Karakoromys, which is a rodent typical of these biozones (Schmidt-Kittler et al., 2007), it could be dated from the Early Oligocene. But, it could more precisely be from the earliest part of the Oligocene due to the occurrence of Ardynomys (Wang \& Meng, 2009). Even if it is a genus more frequently found in Eocene strata, it is also found in the informal biozone A of the Valley of Lakes (Fig. 4).

To date, the different faunas from the Oligocene deposits of Ulantatal include more than 70 species encompassing 8 orders of mammals. Among them, there is an impressive majority of micro-mammals, especially rodents, which encompass at least 50 species belonging to 9 different families (Tables 2 and 3). Some fossils, including notably macro-mammals (i.e., Perissodactyla, Cetartiodactyla, Carnivora and Creodonta) and some small squamates, still remain in the collection of the IVPP to be described and given accurate locality data. Indeed, macro-mammals and a few micro-mammals (i.e., Eulipotyphla, Lagomorpha and Didymoconida) unearthed during the first expeditions (Huang, 1982) were dated imprecisely as "Middle Oligocene", and thus need to be reconsidered (Table 3). The real total number of macro-mammals is low (12 species) and probably underestimated when compared to the number of rodents, which might be due to the differential sampling between the field campaigns. Moreover, although the number of all the Oligocene species of rodents is very close between the Ulantatal area and the Valley of Lakes (more than 50 and 60 species, respectively), the abundance of macro-mammals strongly differs (at least more than 10 and 40 species, respectively; Daxner-Höck et al., 2010, 2014; Maridet et al. 2014a, $\mathrm{b}$, in press). For instance, Cetartiodactyla appear much more abundant in the Valley of Lakes (21 species; Daxner-Höck et al., 2010), than in Ulantatal (3). There are also strong differences regarding other micro-mammals such as Eulipotyphla and Lagomorpha. These observations are likely the result of incomplete data due to sampling bias, even if differential geographical distribution cannot be excluded for the moment. The last point concerns the occurrence of some species during the Late Oligocene at Ulantatal (e.g., Anomoemys lohiculus, Cricetops dormitor, Eucricetodon asiaticus, and Ulaancricetodon badamae), which are only present during the Early Oligocene in the Valley of Lakes. Unfortunately, this issue will be tackled only when all the rodent faunas are described, in order to know if it is a question of dating of UTL sites from Unit II or a matter of differential stratigraphic ranges regarding rodents from Inner and Central Mongolia.

\section{Compositions of rodent paleocommunities and ecological implications}

Muroids, ctenodactyloids and dipodids are the most abundant forms among rodents at Ulantatal in representing about $98 \%$ of the rodent specimens described. Cylindrodontids are less frequent and far less represented, while aplodontoids, eomyids and sciurids constitute the rarest groups. It appears difficult to address the case of the Tsaganomyidae from a temporal viewpoint, since there is no corresponding material known in UTL sites. The same tendencies can be observed in terms of specific richness in the Valley of Lakes, even though tsaganomyid species are as numerous as dipodids, muroids and ctenodactylids (Schmidt-Kittler et al., 2007; Maridet et al., 2014a; Daxner-Höck et al., 2014). Nonetheless, information is so far only partial regarding the abundance of each species in this Mongolian area, since the whole rodent material is not yet accurately described (e.g.; Dipodidae at Ulantatal, Muroidea and a few groups of rodents in the Valley of Lakes). However, while a clear biochronological framework is not yet defined for Central and Eastern Asian areas concerning the Oligocene, it is worth noting that the ctenodactylid Karakoromys is typical from the Early Oligocene, while the eomyid Asianeomys, the dipodoid Litodonomys and the muroid Tachyoryctoidinae are 


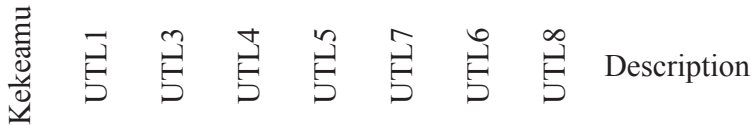

\section{Aplodontidae \\ Prosciurus sp.}

Ninamys arboraptus (Shevyreva, 1967)

Promeniscomys sinensis Wang, 1987

\section{Ctenodactyloidea}

Ageitonomys neimongolensis Wang, 2010

\section{Ctenodactylidae}

Karakoromys decessus Matthew \& Granger, 1923

Karakoromys cf. decessus Matthew \& Granger, 1924

Tataromys sigmodon Matthew \& Granger, 1923

Tataromys minor (Huang, 1985)

Tataromys plicidens Matthew \& Granger 1923

Alashania tengkoliensis Vianey-Liaud et al., 2006

Yindirtemys ulantatalensis (Huang, 1985)

Yindirtemys bohlini (Huang, 1985)

Yindirtemys shevyrevae Vianey-Liaud et al., 2006

Yindirtemys aff. shevyrevae Vianey-Liaud et al., 2006

Yindirtemys deflexus (Teilhard de Chardin, 1926)

Huangomys frequens Schmidt-Kittler et al., 2007

Helanshania deserta Vianey-Liaud et al., 2010

Tataromyinae nov. gen., nov. sp. 2

Tataromyinae nov. gen., nov. sp. 3

Tataromyinae nov. gen., nov. sp. 4

\section{Cylindrodontidae}

Ardynomys sp.

Anomoemys lohiculus (Matthew \& Granger, 1923)

\section{Dipodidae}

Heosminthus sp.

Parasminthus asiae-centralis Bohlin, 1946

Parasminthus tangingoli Bohlin, 1946

Bohlinosminthus parvulus Bohlin, 1946

Gobiosminthus qiui Huang, 1992

?Gobiosminthus sp. Huang, 1992

Shamosminthus tongi Huang, 1992

Ulaancricetodon badamae Daxner-Höck, 2000

Litodonomys huangheensis Wang \& Qiu, 2000

\section{Eomyidae}

Asianeomys sp.

\section{Muroidea}

Eucricetodon asiaticus (Matthew \& Granger, 1923)

Eucricetodon jilantaiensis Gomes Rodrigues et al., 2012

Eucricetodon bagus Gomes Rodrigues et al., 2012

Eucricetodon aff. caducus (Shevyreva, 1967)

Eucricetodon sp. 1

Eucricetodon sp. 2

Eucricetodon sp. 3

Bagacricetodon tongi Gomes Rodrigues et al., 2012

Plesiodipus wangae Gomes Rodrigues et al., 2012

Plesiodipus sp.

Witenia yolua Gomes Rodrigues et al., 2012

Cricetops dormitor Matthew \& Granger, 1923

Pseudocricetops matthewi Gomes Rodrigues et al., 2012

Tachyoryctoidinae indet.

Genus indet.

\section{Sciuridae}

Genus indet.

\section{$+$}

Wang \& Wang, 1991

+ Vianey-Liaud et al., 2013

+ Vianey-Liaud et al., 2013

Wang, 2010

Vianey-Liaud et al., 2006

Wang \& Wang, 1991

$+\quad$ Vianey-Liaud et al., 2006

Vianey-Liaud et al., 2006

Vianey-Liaud et al., 2006

+? Vianey-Liaud et al., 2006

$+\quad$ Vianey-Liaud et al., 2006

+ Vianey-Liaud et al., 2006

+ Vianey-Liaud et al., 2006

Vianey-Liaud et al., 2006

$+\quad$ Vianey-Liaud et al., 2006

+ Vianey-Liaud et al., 2006

Vianey-Liaud et al., 2010

Vianey-Liaud et al., 2006

+ Vianey-Liaud et al., 2006

+ Vianey-Liaud et al., 2006

Wang \& Meng, 2009

Huang, 1993 and this paper

Wang \& Wang, 1991

$+\quad$ Huang, 1992

$+\quad$ Huang, 1992

$+\quad$ Huang, 1992

Huang, 1992

Huang, 1992

+ Huang, 1992

Gomes Rodrigues et al., 2011

This paper

This paper

Gomes Rodrigues et al., 2012

Gomes Rodrigues et al., 2012

Gomes Rodrigues et al., 2012

Gomes Rodrigues et al., 2012

Gomes Rodrigues et al., 2012

Gomes Rodrigues et al., 2012

Wang \& Wang, 1991

$+\quad$ Gomes Rodrigues et al., 2012

$+\quad+$ Gomes Rodrigues et al., 2012

Gomes Rodrigues et al., 2012

+ Gomes Rodrigues et al., 2012

Gomes Rodrigues et al., 2012

Gomes Rodrigues et al., 2012

Gomes Rodrigues et al., 2012

Wang \& Wang, 1991 
not found before the Late Oligocene.

Among all rodent paleocommunities, 9 families or superfamilies have been listed (Table 2). Except for aplodontoids, eomyids and sciurids, which are scarcely present, the other groups were well represented across the Mongolian Plateau, and their stratigraphic ranges cover the entire Oligocene period. Ctenodactylids, dipodids and muroids are the most diversified taxa. While the species richness of Muroidea does not vary significantly from one area to another (considering that Ulaancricetodon is a dipodid; see Gomes Rodrigues et al., 2011), there are more Dipodidae than Ctenodactylidae in the Valley of Lakes (20 and 8 species, respectively) contrary to what it is observed at Ulantatal (9 Dipodidae and 16 Ctenodactylidae). Apart from sampling variation, such differences can emphasize geographical disparities concerning the compositions of rodent communities in the Mongolian Plateau, which could be linked to partitioning of the ecological niches likely due to small local environmental variations. More generally, the size and shape variations are important in ctenodactylids and muroids (Vianey-Liaud et al., 2006; Gomes Rodrigues et al., 2012), and trends toward increasing crown height and more developed crests potentially indicate modifications of ecological niches in

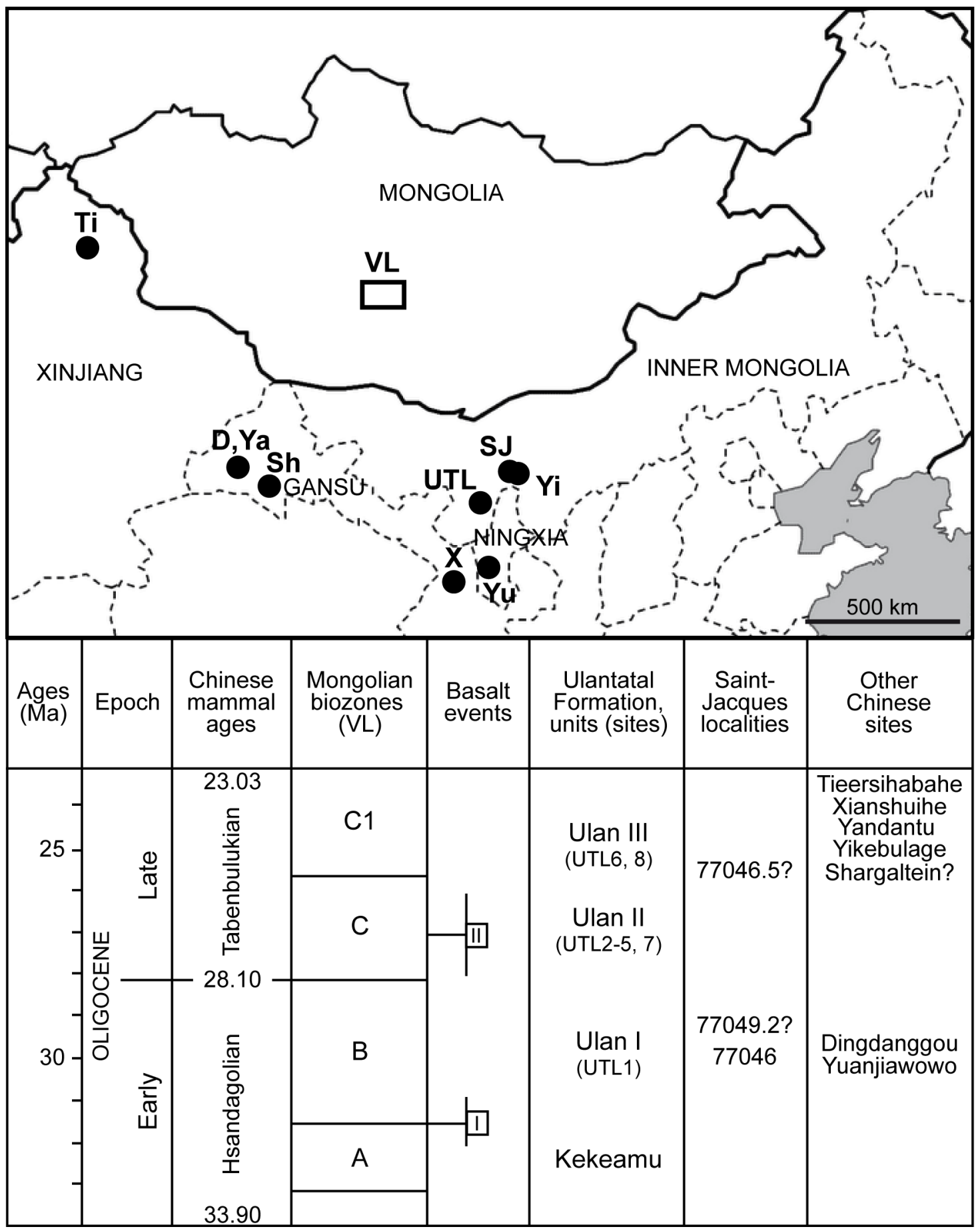

Figure 4. Location of the main Oligocene sites of Mongolia and Northern China, and biostratigraphic correlations according to local Mongolian biozones (modified after Daxner-Höck et al., 2010, 2014). Abbreviations: D, Dingdanggou; Ti, Tieersihabahe; Sh, Shargaltein; SJ, Saint-Jacques; UTL, Ulantatal; VL, Valley of Lakes (see Daxner-Höck et al., 2010 for the detail of each site); Ya, Yandantu; Yi, Yikebulage; Yu, Yuanjiawowo; X, Xianshuihue. 
Table 3. Complementary mammalian faunal list for Kekeamu and surface finds for the Ulantatal areas from early field campaigns.

\begin{tabular}{|c|c|c|c|}
\hline Area & Superfamily/family & Genus and species & References \\
\hline \multirow[t]{4}{*}{ Kekeamu } & Erinaceidae & ?Tupaidon sp. & Wang \& Wang, 1991 \\
\hline & Palaeolagidae & Desmatologus sp. & Wang \& Wang, 1991 \\
\hline & Chalicotheridae & Schizotherium cf. avitum Matthew \& Granger, 1923 & Wang \& Wang, 1991 \\
\hline & Hyracodontidae & Ardynia cf. mongoliensis Matthew \& Granger, 1923 & Wang \& Wang, 1991 \\
\hline \multirow[t]{21}{*}{ Surface collecting } & Feloidea & Paleoprionodon $\mathrm{sp}$. & Huang, 1993 \\
\hline & Amphicyonidae & Cynodictis elegans Matthew \& Granger, 1924 & Huang, 1993 \\
\hline & & ?Amphicynodon sp. & Huang, 1993 \\
\hline & Feliformia & Paleogale sectoria (Gervais, 1852) & Huang, 1993 \\
\hline & Bovoidea & Palaeohypsodontus cf. P. asiaticus Trofimov, 1958 & Huang, 1985 \\
\hline & & Hanhaicerus qii Huang, 1985 & Huang, 1985 \\
\hline & Cervoidea & Eumeryx culminis Matthew \& Granger, 1924 & Huang, 1985 \\
\hline & Hyaenodontidae & Hyaenodon neimongoliensis Huang \& Zhu, 2002 & Huang \& Zhu, 2002 \\
\hline & Didymoconidae & Didymoconus colgatei Matthew \& Granger, 1924 & Meng \& McKenna, 1998 \\
\hline & Erinaceidae & Palaeoscaptor acridens Matthew \& Granger, 1924 & Huang, 1984 \\
\hline & & Paleoscaptor rectus Matthew \& Granger, 1924 & Huang, 1984 \\
\hline & Palaeolagidae & Desmatolagus cf. D. gobiensis Matthew \& Granger, 1923 & Huang, 1987 \\
\hline & & Desmatolagus pusillus Teilhard de Chardin, 1926 & Huang, 1987 \\
\hline & Ochotonidae & Sinolagomys kansuensis Bohlin, 1937 & Huang, 1987 \\
\hline & & Sinolagomys major Bohlin, 1937 & Huang, 1987 \\
\hline & Leporidae & Ordolagus teilhardi (Burke, 1941) & Huang, 1986 \\
\hline & Rhinocerotidae & Cadurcodon sp. & Huang, 1982 \\
\hline & & Aceratherium sp. & Huang, 1982 \\
\hline & Muroidea & Selenomys mimicus Matthew \& Granger, 1923 & Huang, 1982 \\
\hline & Tsaganomyidae & Tsaganomys altaicus Matthew \& Granger, 1923 & Wang, 2001 \\
\hline & & Coelodontomys asiaticus Wang, 2001 & Wang, 2001 \\
\hline
\end{tabular}

a general context of global cooling (Dupont-Nivet et al., 2007) and local aridification and opening of environments. This is supported by dental microwear analyses in these rodents, which show an increase of the potential consumption of abrasive and fibrous plants more frequently found in open habitats (Gomes Rodrigues et al., 2012b).

There are a lot of species that appeared during the latest Oligocene, especially at Ulantatal (i.e., UTL6 and 8) where nearly half of the species are new. That can be explained by a slight warming event recorded at the end of the Oligocene, which could have induced a moderate faunal turnover and a slight change of environments (de Man \& Van Simayes, 2003; Maridet et al., 2009; Gomes Rodrigues et al., 2012a). This is particularly shown by the concomitant occurrence of eomyids, aplodontids and sciurids specific of more forested habitats, as well as small muroids, such as Bagacricetodon tongi. Fossorial rodents are also well represented in the Mongolian Plateau during the Oligocene, and are notably characterized by highcrowned teeth, and "mole-rat-like" skulls observed in Tsaganomyidae. Cylindrodontids are typical of the Early Oligocene (e.g., Ardynomys), and only one occurrence is registered in the Late Oligocene deposits of Ulantatal (this work). Tsaganomyids are common mainly in the Early Oligocene, including specimens from Ulantatal (Wang, 2001). In the Mongolian Plateau, Cyclomylus and Coelodontomys species are specific of the Early Oligocene, while the occurrence of Tsaganomys altaicus extended to the Early Miocene. The decline of these groups during the Late Oligocene could be partly related to the appearance of fossorial muroids, the Tachyoryctoidinae (Wang \& Qiu, 2012). Further researches are needed to address the main evolutionary, ecological and migratory events of the whole rodent paleocommunities in this part of Asia during the Oligocene to make reliable comparisons with other regions.

\section{PROSPECTS}

Contrary to the Valley of Lakes, faunal lists from other Northern Chinese areas are generally sparse, and the relative abundance of each taxon is not always specified. In this context, even if it remains premature to draw comparisons with Ulantatal, it seems important to list them to show first their geographical and chronological interests for further studies (Fig. 4). The nearest sites from Ulantatal are located at Saint-Jacques, belonging to the Wulanbulage Formation, which is well-known for having yielded abundant mammal fossils (Wang et al., 1981). Among the vast number of sites, the best documented are 77046, 77046.5 and 77049.2 (Wang, 1987a,b, 1997, 2001; Wang \& Emry, 2001). There is also a very close site from the Yikebulage Formation (Wang et al., 1981). Apart from Inner Mongolia, other Northern Chinese sites bear Oligocene faunas, such as the Yuanjiawowo fauna from the Haiyuan area located in Ningxia (Wang et al., 1994). Not far from there, in Eastern Gansu, the lower member of the Xianshuihe Formation (Lanzhou Basin; Wang \& Qiu, 2000a, b) includes deposits, which are latest Oligocene in age (Xiagou and Shangxigou). The geological area of western Gansu originally described by Bohlin $(1937,1946)$ and including sites from Shargaltein (Wang \& Qiu, 2003) and Taben-Buluk, has been investigated recently. Taben-Buluk, currently known as the Danghe area and corresponding to the Paoniuquian Formation, consists of a lower part including the Dingdanggou fauna (Wang \& Qiu 2004) and an upper part including the Yandantu fauna (Bohlin's Yindirte fauna; Wang, 2003; Wang et al., 2003; Wang et al., 2008). In the northwestern part of China, the Tieersihabahe section of the Junggar Basin (Xinjiang) comprises a few sites accurately dated from the latest Oligocene (Meng et al., 2006). Because of the importance of these different Oligocene sites with distinct ages, it appears crucial to update their stratigraph- 
ic characteristics and to accurately date and describe their fauna in order to discuss the distribution of specific taxa in Central and Eastern Asia, and both the structure and evolution of the different mammal paleocommunities in a context of global climate change and local environment modifications.

\section{ACKNOWLEDGMENTS}

We are grateful to the Institute of Vertebrate Paleontology and Paleoanthropology (IVPP) in Beijing, which allowed us to study these rodent faunas that were collected during their last expedition in 1987, and to N. Schmidt-Kittler who involved us in this study. We also thank the Academia Sinica (China) and the Max Planck Gesellschaft (Germany) for their important contribution in this work through their financial support concerning the field campaigns at Ulantatal. We are grateful to the anonymous reviewers for their comments and suggestions, which permitted to improve the quality of this manuscript. This is ISE-M publication 2014-068.

\section{BIBLIOGRAPHY}

Bohlin, B., 1937. Oberoligozäne Säugetiere aus dem Shargaltein-tal (Western Kansu). Sino-swedish Expedition Publication.

Bohlin, B., 1946. The Fossil Mammals from the tertiary deposit of Taben-Buluk, Western Kansu, Part II, Simplicidentata, Carnivora, Artiodactyla, Perissodactyla and Primates. Sino-swedish Expedition Publication.

Daxner-Höck, G., Badamgarav, D., 2007. Geological and stratigraphic setting. In: Daxner-Höck, G. (Ed.), Oligocene-Miocene Vertebrates from the Valley of Lakes (Central Mongolia): Morphology, phylogenetic and stratigraphic implications. Annalen des Naturhistorischen Museums in Wien. pp. 1-24

Daxner-Höck, G., Badamgarav, D. Erbajeva, M., 2010. Oligocene stratigraphy based on a sediment-basalt association in Central Mongolia (Taatsiin Gol and Taatsiin Tsagaan Nuur Area, Valley of Lakes): review of Mongolian-Austrian project. Vertebrata Pa1Asiatica 48, 348-366.

Daxner-Höck, G., Badamgarav, D., Maridet, O., 2014. Dipodidae (Rodentia, Mammalia) from the Oligocene and Early Miocene of Mongolia. Annalen des Naturhistorischen Museums in Wien $116,131-214$.

Dupont-Nivet, G., Krijgsman, W., Langereis, C. G., Abels, H. A., Dai, S., Fang, X., 2007. Tibetan plateau aridification linked to global cooling at the Eocene-Oligocene transition. Nature 445, 635-638.

Gomes Rodrigues, H., Charles, C., Marivaux, L., Vianey-Liaud, M., Viriot, L., 2011. Evolutionary and developmental dynamics of the dentition in Muroidea and Dipodoidea (Rodentia, Mammalia). Evolution and Development 13, 260-268.

Gomes Rodrigues, H., Marivaux, L., Vianey-Liaud, M., 2012a. The Cricetidae (Rodentia, Mammalia) from the Ulantatal area (Inner Mongolia, China): New data concerning the evolution of Asian cricetids during the Oligocene. Journal of Asian Earth Sciences $56,160-179$.

Gomes Rodrigues, H., Marivaux, L., Vianey-Liaud, M., 2012b. Expansion of open landscapes in Northern China during the Oligocene induced by dramatic climate changes: Paleoecological evidence. Palaeogeography, Palaeoclimatology, Palaeoecology 358-360, 62-71.

Höck, V., Daxner-Höck, G., Schmid, H. P., Badamgarav, D., Frank, W., Furtmuller, G., Montag, O., Barsbold, R., Khand, Y., Sodov, J., 1999. Oligocene-Miocene sediments, fossils and basalts from the Valley of Lakes (Central Mongolia) - an integrated study. Mitteilungen der Osterreichischen Geologischen Gesellschaft 90, 83-125.

Huang, X., 1982. Preliminary observations on the Oligocene deposits and mammalian fauna from Alashan Zuoqi, Nei Mongol. Vertebrata PalAsiatica iatica 20, 337-349.

Huang, X. 1984. Fossil Erinaceidae (Insectivora, Mammalia) from the Middle Oligocene of Ulantatal, Alxa Zouqi, Nei Mongol. Vertebrata PalAsiatica 22, 305-309.

Huang, X. 1985. Fossil bovids from the middle Oligocene of Ulantatal, Nei Mongol. Vertebrata PalAsiatica 23, 152-161.

Huang, X., 1986. Fossil leporids from the middle Oligocene of Ulantatal, Nei Mongol. Vertebrata PalAsiatica 24, 274-284.

Huang, X., 1987. Fossil ochotonids from the middle Oligocene of Ulantatal, Nei Mongol. Vertebrata PalAsiatica 25, 260-282.

Huang, X., 1992. Zapodidae (Rodentia, Mammalia) from the middle Oligocene of Ulantatal, Nei Mongol. Vertebrata PalAsiatica 30, 249-286.

Huang, X., 1993a. Cylindrodontidae (Rodentia, Mammalia) from the middle Oligocene of Ulantatal, Nei Mongol. Vertebrata PalAsiatica 31, 33-43.

Huang, X., 1993b. Note on some carnivorous remains from the Middle Oligocene of Ulantatal, Nei Mongol. Vertebrata PalAsiatica 31, 294-303.

Huang, X., Zhu, B., 2002. Creodont (Mammalia) remains from the early Oligocene of Ulantatal, Nei Mongol. Vertebrata PalAsiatica $40,17-22$.

Kimura, Y., 2010. New material of dipodid rodents (Dipodidae, Rodentia) from the early Miocene of Gashunyinadege, Nei Mongol, China. Journal of Vertebrate Paleontology 30, 1860-1873.

Kowalski, K., 1974. Middle Oligocene rodents from Mongolia. Results of the Polish-Mongolian Paleontological expeditions Part V. Paleontologica Polonica 30, 147-178.

Li, C.-K., Qiu, Z., 1980. Early Miocene mammalian fossils of Xining basin, Qinghai. Vertebrata Palasiatica 18, 198-214.

Lopatin, A.V., 2000. New Early Miocene Aplodontidae and Eomyidae (Rodentia, Mammalia) from the Aral Formation of the Altynshokysu Locality (North Aral Region). Paleontologicheskii Zhurnal 34, 81-85

Lopatin, A.V., 2004. Early Miocene small mammals from the North Aral region (Kazakhstan) with special reference to their biostratigraphic significance. Paleontologicheskii Zhurnal 38(Suppl. 3), 217-323.

de Man, E., Van Simayes, S., 2004. Late Oligocene Warming Event in the southern North Sea basin: benthic foraminifera as paleotemperature proxies. Netherlands Journal of Geosciences/Geology en Mijnbouw 83, 227-239.

Maridet, O., Daxner-Höck, G., Badamgarav, D., Göhlich, U.B., 2014a. Cricetidae (Rodentia, Mammalia) from the Valley of Lakes (Central Mongolia): focus on the Miocene record. Annalen des Naturhistorischen Museums in Wien 116, 247-169.

Maridet, O., Daxner-Höck, G., Badamgarav, D., Göhlich, U.B., 2014b. New discoveries of Sciurids (Rodentia, Mammalia) from the Valley of Lakes (Central Mongolia). Annalen des Naturhistorischen Museums in Wien 116, 271-291.

Maridet, O., Daxner-Höck, G., Badamgarav, D., Göhlich, U. B., in press. The eomyid rodents (Mammalia) from the Oligocene and Miocene of the Valley of Lakes (Central Mongolia). Palaontologische Zeitschrift.

Maridet, O., Wu, W., Ye, J., Bi, S., Ni, X., Meng, J., 2009. Eucricetodon (Rodentia, Mammalia) from the Late Oligocene of the Junggar basin, northern Xinjiang, China. American Museum Novitates 3665, 1-21.

Marivaux, L., Vianey-Liaud, M., Jaeger, J.-J., 2004. High-level phylogeny of early Tertiary rodents: dental evidence. Zoological Journal of the Linnean Society 142, 105-134.

Matthew, W.D., Granger, W., 1923. Nine new rodents from the Oligocene of Mongolia. American Museum Novitates 102, $1-10$.

Meng, J., Ye, J., Wu, W.-Y., Yue, L.-P., Ni, X.-J., 2006. A recommended boundary stratotype section for Xiejian Stage from northern Junggur Basin: implications to related bio-chronostratigraphy and environmental changes. Vertebrata Palasiatica 44, 205-236.

Russell, D. E., Zhai R.-J., 1987. The Paleogene of Asia: mammals 
and stratigraphy. Mémoires du Muséum National d'Histoire Naturelle, Sciences de la Terre.

Schmid-Kittler, N., Vianey-Liaud, M., Marivaux, L., 2007. The Ctenodactylidae (Rodentia, Mammalia). In Daxner-Höck, G. (Ed.), Oligocene-Miocene Vertebrates from the Valley of Lakes (Central Mongolia): Morphology, phylogenetic and strtigraphic implications. Annalen des Naturhistorischen Museums in Wien. pp. 173-215.

Vianey-Liaud, M., Gomes Rodrigues, H., Marivaux, L., 2010. A New Oligocene Ctenodactylinae (Rodentia, Mammalia) from Ulantatal (Nei Mongol): new insight on the phylogenetic origins of the modern Ctenodactylidae. Zoological Journal of the Linnean Society 160, 531-550.

Vianey-Liaud, M., Gomes Rodrigues, H., Marivaux, L., 2013. Early adaptive radiations of Aplodontoidea (Rodentia, Mammalia) on the Holarctic region: systematics, and phylogenetic and paleobiogeographic implications. Paläontologische Zeitschrift 87, 83-120

Vianey-Liaud, M., Schmidt-Kittler, N., Marivaux, L., 2006. The Ctenodactylidae (Rodentia) from the Oligocene of Ulantatal (Inner Mongolia, China). Palaeovertebrata 34, 111-205.

Walsh, S. L., Storer, J. E., 2008. Cylindrodontidae. In Janis, C. M., Gunnell, G. F., Uhen, M. D. (Eds.), Evolution of Tertiary Mammals of North America, volume 2: Small Mammals, Xenarthrans and Marine Mammals. Cambridge University Press, pp. 336-354.

Wang, B., 1987a. Discovery of Aplodontidae (Rodentia, Mammalia) from middle Oligocene of Nei Mongol, China. Vertebrata PalAsiatica $25,32-45$.

Wang, B., 1987b. Discovery of Cricetids (Rodentia, Mammalia) from Middle Oligocene of Nei Mongol, China. Vertebrata PalAsiatica 25, 187-198.

Wang, B., 1997. The mid-Tertiary Ctenodactylidae (Rodentia, Mammalia) of eastern and central Asia. Bulletin of the American Museum of Natural History 234, 1-88.

Wang, B., 2001. On Tsaganomyidae (Rodentia, Mammalia) of Asia. American Museum Novitates 3317, 1-50.

Wang, B., 2002. Discovery of Late Oligocene Eomyodon (Rodentia, Mammalia) from the Danghe area, Gansu, China. Vertebrata Palasiatica 40, 139-145.

Wang, B., 2003. Dipodidae (Rodentia, Mammalia) from the mid-Tertiary deposits in Danghe area, Gansu, China. Vertebrata PalAsiatica $41,89-103$.

Wang, B., 2010. Ageitonomys neimongolensis gen. et sp. nov. (Ctenodactyloidea, Rodentia, Mammalia) from Early Oligocene of Nei Mongol, China. Vertebrata PalAsiatica 48, 79-83.
Wang, B., Chang, J., Meng, X., Chen J., 1981. Stratigraphy of the Upper and Middle Oligocene of Qianlishan District, Nei Mongol (Inner Mongolia). Vertebrata PalAsiatica 19, 26-34.

Wang, B., Emry, R. J., 1991. Eomyidae (Rodentia: Mammalia) from the Oligocene of nei Mongol, China. Journal of Vertebrate Paleontology 11, 370-377.

Wang, B., Meng J., 2009. Ardynomys (Cylindrodontidae, Rodentia) from Nei Mongol, China. Vertebrata PalAsiatica 47, 240-244.

Wang, B., Qiu, Z., 2000a. Dipodidae (Rodentia, mammalia) from the lower member of Xianshuihe Formation in Lanzhou Basin, China. Vertebrata PalAsiatica 38, 5-35.

Wang, B., Qiu, Z., 2000b. Micromammal fossils from the red mudstone of Lower Member of Xianshuihe Formation in Lanzhou Basin, China. Vertebrata PalAsiatica 38, 255-273.

Wang, B., Qiu, Z., 2003. Notes on Early Oligocene Ursids (Carnivora, Mammalia) from Saint Jacques, Nei Mongol, China. Bulletin of American Museum of Natural History 279, 116-124.

Wang, B., Qiu, Z., 2004. Discovery of early Oligocene mammalian fossils from Danghe Area, Gansu. Vertebrata PalAsiatica 42, 130-143.

Wang, B., Qiu, Z., 2012. Tachyoryctoides (Muroidea, Rodentia) fossils from Early Miocene of Lanzhou Basin, Gansu Province, China. Swiss Journal of Paleontology 131, 107-126.

Wang, B., Wang, P., 1991. Discovery of Early Medial Oligocene Mammalian Fauna from Kekeamu, Alxa Left Banner, Nei Mongol. Vertebrata PalAsiatica 29, 64-71.

Wang, B., Yan, Z., Lu, Y., Chen, G., 1994. Discovery of two mid-Tertiary mammalian faunas from Haiyuan, Ningxia, China. Vertebrata PalAsiatica 32, 285-296.

Wang, X., Wang, B., Qiu, Z., 2008. Early explorations of Tabenbuluk region (western Gansu Province) by Birger Bohlin-Reconciling classic vertebrate fossil localities with modern stratigraphy. Vertebrata PalAsiatica 46, 1-19.

Wang, X., Wang, B., Qiu, Z., Xie, G., Xie, J., Downs, W., Qiu, Z., Deng, T., 2003. Danghe area (western Gansu, China) biostratigraphy and implications for depositional history and tectonics of northern Tibetan Plateau. Earth and Planetary Science Letters 208, 253-269.

Wood, A. E., Wilson, R. W., 1936. A suggested nomenclature of the cheek teeth of rodents. Journal of Paleontology 10, 388.

Wu, W.-Y., Meng, J., Ye, J., Ni, X.-J., 2006. The first finds of eomyids (Rodentia) from the Late Oligocene - Early Miocene of the Northern Junggar Basin, China. Beiträge zur Paläontologie 30, 469-479. 